\title{
A REALIZAÇÃO DO SUJEITO PRONOMINAL EM FLORIANÓPOLIS
} THE REALIZATION OF THE SUBJECT PRONOUN IN FLORIANÓPOLIS

\author{
Diego Rafael Vogt \\ Mestre em Linguística pela Universidade Federal de Santa Catarina \\ diegorafavogt@hotmail.com \\ Bruno Cardoso \\ Mestre em Linguística pela Universidade Federal de Santa Catarina \\ brunocardosolp@yahoo.com.br
}

\begin{abstract}
RESUMO: Este artigo $^{1}$, de base teórica variacionista, discute a realização do sujeito pleno ou nulo - na cidade de Florianópolis, mais precisamente na comunidade rural da Costa da Lagoa. A investigação do fenômeno é empreendida a partir de vasta bibliografia no assunto, a destacar a tese de Duarte (1993), que tem defendido a mudança no padrão sintático do PB de um estágio de parâmetro pro-drop positivo para parâmetro pro-drop negativo, desencadeado a partir da perda de flexões no paradigma verbal do PB. Diante disso, este estudo desenvolve uma investigação empírica no bairro Trindade (área urbana) e na comunidade rural da Costa da Lagoa, buscando mostrar que esse fenômeno sintático em variação se encontra muito mais intimamente correlacionado a fatores internos do que a fatores externos, o que atestam os trabalhos até aqui desenvolvidos sobre o assunto dentro de um enfoque variacionista.
\end{abstract}

PALAVRAS-CHAVE: Sujeito nulo. Sujeito pronominal. Princípios e parâmetros.

ABSTRACT: This paper discusses, from a variationist theoretical basis, the realization of pronominal subjects - full or null - in two communities of the city of Florianópolis/SC: Trindade and Costa da Lagoa. The investigation of the phenomenon takes back the work of Duarte (1992), which defends a change in the syntactic pattern of Brazilian Portuguese from a stage of a positive pro-drop parameter to a negative pro-drop parameter, initiated from the loss of inflections in the Brazilian Portuguese verbal paradigm. From this perspective, this paper develops a preliminary empirical research, which seeks to verify if this phenomenon in syntactic variation is more closely correlated to internal factors than to external factors of language, in order to confirm the variationist studies about the subject developed so far.

KEYWORDS: Null subject. Pronominal subject. Principles and parameters.

\footnotetext{
${ }^{1}$ Este artigo corresponde ao trabalho final da disciplina de Sociolinguística e Dialetologia ministrada no Programa de Pós-Graduação em Linguística da Universidade Federal de Santa Catarina (PPGLg/UFSC), no primeiro semestre de 2012.
}

Work. Pap. Linguíst., 15(2): 86-102, Florianópolis, ago/dez, 2014 


\section{INTRODUÇÃO}

A sintaxe do português brasileiro (PB) tem sofrido cruciais modificações em sua estrutura nos últimos tempos, principalmente na virada do século XIX para o século $\mathrm{XX}$. Mudanças sintáticas têm revestido o PB de novas nuances e singularidade próprias, distanciando-o cada vez mais do padrão linguístico europeu. A sociolinguística brasileira tem se alimentado dessas mudanças para promover novos avanços em sua teoria e novas possibilidades de interface, que alavancam a compreensão mais acurada de toda a complexidade envolvida na tessitura dessa nova sintaxe brasileira.

O texto pioneiro de Tarallo e Kato (2011 [1988]) já proclamava o quão saudável seria uma interface gerativismo-sociolinguística. Tempos depois, Tarallo (1992) traça um panorama da sintaxe brasileira, mirando sua lupa científica para a cadeia de mudanças sintáticas havidas na virada do século XIX para o século XX. Tal virada do século coincidiu com uma virada linguística no português brasileiro, deflagrando mudanças linguísticas como uma reação em cascata. Em sua argumentação, Tarallo (1992) diagnostica a emergência de uma gramática brasileira decorrida na troca de século e o faz lançando mão de um conjunto de fenômenos sintáticos: (i) a reorganização do sistema pronominal e, por conseguinte, a implementação do objeto nulo em nosso sistema linguístico, por um lado, e, por outro lado, a realização mais frequente do sujeito lexical; (ii) a mudança sintática havida nas estratégias de relativização como consequência direta da mudança no sistema pronominal; (iii) a reorganização dos padrões sentenciais básicos (ordem SVO); e (iv) a alteração nos padrões sentenciais em perguntas diretas e indiretas.

Assumindo o princípio proposto por Tarallo (1992) de que a realização do sujeito no PB está intimamente relacionada à reorganização do sistema pronominal, nosso artigo discutirá a realização do sujeito - pleno ou nulo - em duas localidades da cidade de Florianópolis/SC, tentando estabelecer uma possível relação entre esse fenômeno sintático e grupos de fatores sociais ou extralinguísticos. Por conta disso, discutiremos também alguns grupos de fatores internos da língua que podem ser primordiais na retenção ou não do sujeito pleno.

$\mathrm{Na}$ seção seguinte, seção 1, faremos uma discussão mais robusta sobre a realização do sujeito pleno no $\mathrm{PB}$ do ponto de vista da teoria gerativa e também traremos a lume alguns trabalhos sociolinguístico-paramétricos que têm se debruçado sobre esse fenômeno e não têm passado incólume por diferentes interpretações. Na seção 2, apresentamos a metodologia de nossa pesquisa, as hipóteses que norteiam o nosso trabalho e o envelope de variação que pretendemos explorar. Na seção 3, são apresentados os resultados da pesquisa, bem como a discussão acerca deles, encerrando, por fim, com breves considerações sobre o assunto.

\section{REVISÃO DA LITERATURA}

\subsection{Sobre o sujeito nulo}

No decorrer das pesquisas linguísticas, tem-se apontado um aspecto empírico das línguas naturais que parece já estar consolidado nas descrições gramaticais: enquanto há línguas que permitem que o sujeito pronominal seja omitido na $\mathrm{PF}^{2}$ de uma sentença finita (ou seja, permitem que o pronome sujeito não esteja lexicalmente presente), há línguas que inibem totalmente essa permissão, tornando obrigatória a

\footnotetext{
${ }^{2}$ Phonological Form.
}

Work. Pap. Linguíst., 15(2): 86-102, Florianópolis, ago/dez, 2014 
realização do pronome sujeito em todas as sentenças. Ao primeiro grupo pertencem línguas como o italiano e o espanhol, enquanto que ao segundo pertencem línguas como o inglês e o francês, como podemos ver nos exemplos abaixo:

(1) pro $^{3}$ Parla il cinese. (italiano)

(2) pro Habla chino. (espanhol)

(3) She speaks Chinese. (inglês)

(4) Elle parle le chinois. (francês)

De acordo com Figueiredo Silva (1996), um segundo aspecto observado decorre diretamente desse primeiro: as línguas que autorizam um pronome nulo na posição de sujeito das sentenças finitas possuem uma morfologia verbal capaz de identificar esse pronome nulo e lhe garantir uma interpretação correta. Desse modo, a interpretação das categorias pro em (1) e (2) está garantida pelos morfemas de número e pessoa dos verbos 'parla' e 'habla', respectivamente. Já em (3) e (4) é obrigatório que se pronunciem os pronomes lexicais 'she' e 'elle', respectivamente, na posição de sujeito dessas sentenças, pois os verbos 'speaks' e 'parle' não possuem morfologia verbal suficiente para atribuir a interpretação correta das informações de número e pessoa gramatical aos sujeitos de suas sentenças ${ }^{5}$.

Esses dois aspectos apresentados têm sido considerados as principais características daquilo que a literatura em sintaxe gerativa tem chamado de o parâmetro do sujeito nulo (parâmetro pro-drop). Na próxima seção estaremos apresentando a definição clássica do parâmetro pro-drop, a partir da literatura gerativista, e mostrando como esse parâmetro se aplica ao PB, bem como as dificuldades dessa aplicação.

\subsubsection{O parâmetro pro-drop}

Entre as décadas de 1980 e 1990, o programa gerativista passou a focar suas investigações dentro de um modelo teórico que ficou conhecido como a teoria de princípios e parâmetros, inicialmente apresentada por Chomsky (1981). Esse modelo captura o postulado de que as línguas possuem princípios que regem o seu funcionamento (ideia estabelecida desde os primórdios do programa gerativista, na década de 1960) e estende a noção de parâmetro como o modo com que o princípio se desenvolve dentro das diferentes línguas. Grosso modo, ao tratarmos da questão do sujeito nulo, podemos caracterizá-la do seguinte modo dentro desse modelo: o princípio é de que toda língua possui sujeito; o parâmetro aponta a possibilidade de uma língua

\footnotetext{
${ }^{3}$ Pronome nulo [-anafórico; + pronominal].

${ }^{4}$ A flexão de número é marcada, nesses verbos, por morfema $\varnothing$.

5 O verbo 'speaks', do inglês, e verbo 'parle', do francês, pertencem a paradigmas verbais que não distinguem flexões de número e flexões de pessoa específicas para cada um dos pronomes pessoais sujeitos que essas línguas admitem, o que, devido a essa ambiguidade, impossibilita a interpretação correta das informações de número e pessoa do sujeito sem a presença explícita do mesmo. Em francês, por exemplo, os pronomes sujeito de primeira pessoa do singular e terceira pessoa do singular, no presente do indicativo, concordam com as mesmas terminações verbais - 'je parle le chinois' ('je', primeira pessoa singular) e 'elle parle le chinois' ('elle', terceira pessoa do singular) - o que mostra que o verbo 'parle' não possui morfologia verbal suficiente para especificar as informações de número e pessoa do sujeito das sentenças em que ele é o verbo matriz.
} 
omitir o sujeito (parâmetro positivo) ou exigir que ele seja lexicalmente pronunciado (parâmetro negativo). Desse modo, o princípio é sempre o mesmo para todas as línguas, o que varia é o modo como elas marcam o parâmetro.

O postulado de um parâmetro é justificado a partir de uma série de propriedades sintáticas que confluem dentro das línguas. Chomsky (1981) lista cinco propriedades que caracterizam o parâmetro pro-drop:
a. Sujeito nulo;
b. Inversão livre do sujeito em orações principais;
c. Movimento WH "longo" do sujeito;
d. Pronome lembrete nulo em orações encaixadas;
e. Aparente violação do filtro "that $t$ ".

Essas propriedades são características de línguas pro-drop, não se verificando nas línguas não-pro-drop. De acordo com Figueiredo Silva (1996), Chomsky (1981) mostra que a confluência dessas propriedades sintáticas nas línguas pro-drop parece estar relacionada a uma capacidade que o nódulo $\operatorname{Agr}^{6}$ tem de reger adequadamente a posição de sujeito nessas línguas, enquanto que nas línguas não-pro-drop o Agr estaria desprovido dessa capacidade. Desse modo, mais uma vez, especula-se, que seja a morfologia verbal "rica" das línguas pro-drop a principal responsável pelo licenciamento de pronomes sujeitos nulos.

\subsubsection{O sujeito nulo no PB}

Uma língua pro-drop genuína deve apresentar as cinco propriedades sintáticas mencionadas na seção anterior. Esse postulado é um problema para o PB, pois essa língua parece estar cada vez mais em desacordo com a propriedade de "inversão livre do sujeito em orações principais".

Nunes de Souza et al. (2010) apresentam resultados dos estudos de Berlinck $(1988 ; 1995)$ e de Coelho $(2000 ; 2006)$, que apontam que o PB tem perdido cada vez mais a possibilidade de inversão verbo-sujeito em sentenças matrizes, mostrando-se cada vez mais enrijecido na configuração S-V-O. Figueiredo Silva (1996) mostra que o PB não possui a opção paramétrica de atribuição de Caso Nominativo em posição pósverbal, o que justifica o fato de a impossibilidade da ordem verbo-sujeito estar se consolidando nessa língua.

O desacordo do PB com a propriedade 'b.' do parâmetro pro-drop tem sido tratado de diferentes formas pela literatura. Dentre diferentes maneiras de se explicar esse desencontro, duas das propriedades têm ganhado destaque especial: i) a hipótese de que há uma mudança paramétrica em curso no $\mathrm{PB}$, de pro-drop positivo para pro-drop negativo; ou ii) a hipótese de que o PB não é uma língua pro-drop, e que a presença de argumentos nulos nessa língua está relacionada a um parâmetro distinto do pro-drop.

Figueiredo Silva (1996) aponta que a entrada das formas você/vocês e a gente no paradigma pronominal do PB tem levado à simplificação do paradigma flexional do

\footnotetext{
${ }^{6}$ Nódulo de concordância de número e pessoa.
} 
PB. Uma vez que há, para cada pessoa do discurso (exceto a primeira pessoa do singular), uma forma que concorda com verbos de terceira pessoa (singular e plural), acaba ocorrendo "uma redução relativamente radical da morfologia verbal, com a consequente perda da representação do traço de pessoa; o único traço que continua sendo sistematicamente representado é o de número" (FIGUEIREDO SILVA, 1996, p. 79). Duarte (1993) defende a tese de que essa mudança no paradigma flexional tem desencadeado o curso de uma mudança paramétrica no $\mathrm{PB}$, de parâmetro pro-drop positivo para parâmetro pro-drop negativo. A autora fundamenta sua argumentação em uma análise sociolinguística de dados que apontam para uma realização fonológica cada vez maior do sujeito pronominal.

Modesto (2004) apresenta uma proposta alternativa para esse problema, alegando que o PB não é uma língua pro-drop, mas uma língua com parâmetro orientado para o discurso. O autor afirma que o parâmetro do sujeito nulo está, de fato, estritamente relacionado à morfologia verbal "rica", e que, por isso, línguas como o chinês, que licenciam sujeitos nulos sem possuir nenhuma morfologia verbal, não pertencem ao grupo das línguas pro-drop, mas sim línguas cujos argumentos nulos estão relacionados a outro tipo de parâmetro: "um parâmetro que distingue línguas orientadas para a sentença e línguas orientadas para o discurso" (MODESTO, 2004, p. 121). Modesto segue, para o PB, a mesma análise que Huang (1984) propôs para o chinês, enquadrando ambas as línguas como línguas de tópico discursivo proeminente ${ }^{7}$.

Apesar de a proposta de Modesto (2004) ser uma alternativa bastante interessante para o tratamento do sujeito nulo no $\mathrm{PB}$, não a abordaremos neste trabalho. Nós apenas a apresentamos com o intuito de mostrar que a teoria do parâmetro pro-drop não é a única possível de ser levada em conta na descrição desse aspecto gramatical, ficando como sugestão, para trabalhos futuros, que se analise o sujeito nulo no PB a partir de propostas alternativas como a do parâmetro orientado para o discurso. Neste trabalho, seguiremos a proposta de Duarte (1993), considerando que o PB é uma língua pro-drop. Nossa análise buscará avaliar a força das hipóteses a respeito das mudanças nos paradigmas pronominal e flexional como ocasionadoras da prevalência da realização lexical dos pronomes sujeitos no $\mathrm{PB}$, a partir dos dados de fala dos informantes de Florianópolis.

\subsection{Estudos variacionistas}

Este artigo se assenta em base teórica variacionista de Wiliam Labov, ao mesmo tempo em que procuraremos uma interpretação para o fenômeno linguístico (a realização dos pronomes-sujeito) em estudo nos postulados da teoria gerativa. Essa perspectiva de integração entre uma linguística de regras de um lado e uma ciência da probabilidade de outro veio à tona de forma genuína em célebre artigo de Tarallo e Kato (1988). Essa perspectiva de integração tem sido perseguida em vários trabalhos de análise sintático-variacionista nas duas últimas décadas. Embora os postulados gerativistas sejam um caminho interpretativo para os fenômenos sintáticos em processo de mudança, é imprescindível admitir aqui a concepção laboviana de que a língua é um sistema heterogêneo, dotada de variação inerente e possuidora de diferenciação ordenada (WLH, 1968). Assim, acreditamos que os processos em variação na língua não são a-sistêmicos nem disfuncionais, nem provocam colapso na estrutura linguística.

\footnotetext{
${ }^{7}$ A análise de Modesto (2004) captura intuições a respeito do tópico discursivo no PB que já apareciam no trabalho de Eunice Pontes de 1986, 'Sujeito: da sintaxe ao discurso'.
}

Work. Pap. Linguíst., 15(2): 86-102, Florianópolis, ago/dez, 2014 
Sendo um processo regulado, ordenado e sistemático, a variação linguística se dá através de regras, no caso de regras variáveis, ao mesmo tempo em que sobre essas regras variáveis incidem fatores catalisadores ou inibidores do processo em mudança, fatores estes que são de ordem interna, externa e estilística, tal como proposto pela teoria sociolinguística.

Imbuídos de tais pressupostos, e dada a limitação deste texto, nos deteremos em alguns fatores internos e externos, que, acreditamos, possam estar agindo sobre a nossa variável linguística em foco, qual seja, a realização ou não do sujeito pronominal no português brasileiro no dialeto florianopolitano.

Diante disso, apresentamos a seguir uma descrição sucinta de dois trabalhos de base teórica variacionista que abordaram o assunto e que nos oferecerão possibilidades de variáveis independentes a serem exploradas em nossa pesquisa.

\subsubsection{Duarte (1993)}

Duarte (1993) em tese sobre a variação da realização ou não do sujeito pronominal no PB desenvolveu um estudo quantitativo integrando os postulados variacionistas labovianos com a teoria de princípios e parâmetros de Chomsky. A autora defende a tese de que os parâmetros do português brasileiro no que diz respeito à realização do sujeito pronominal estariam seguindo um trajeto de mudança.

Duarte acredita que a riqueza flexional dos paradigmas verbais de uma língua engatilha a possibilidade de omissão do sujeito em sentenças finitas. Em sua tese, então, a pesquisadora vai em busca de indícios em peças populares do Rio de Janeiro englobando o meio do século XIX até o final do século XX - de que na virada do século retrasado o $\mathrm{PB}$ começou a diminuir consideravelmente o número de ocorrências de sujeito nulo.

A título de evidência empírica a esse respeito, os dados catalogados por Duarte são reveladores. Tais dados apontam para uma nítida preferência pelo sujeito nulo nos três primeiros períodos analisados (1845, 1882 e 1918), com índices de até $80 \%$ de sujeito nulo. A partir de 1918, começa a ocorrer um aumento na realização do sujeito pronominal, com índices chegando a pouco mais de 50\% na década de 1930 . E eis que a explosão de sujeitos plenos se dá no acervo de dados da autora em 1992, com pouco mais de $20 \%$ de sujeitos nulos. Diante de tantos indícios, a autora conclui que "a redução no quadro de desinências verbais alterou as características de língua 'pro-drop' que o português do Brasil apresentava antes de 1937" (DUARTE, 1993).

\subsubsection{Nunes de Souza et al. (2010)}

A partir de Duarte (1993), muitos trabalhos pelo Brasil, desde então, têm fornecido evidências empíricas que corroboram as hipóteses da autora. Mencionamos aqui o trabalho de Nunes de Souza et al. (2010), que examinaram esse fenômeno em redação de alunos de escolas públicas de Florianópolis. As autoras encontraram um alto índice de preenchimento de sujeito (67\%) nos textos escritos dos alunos, bem como evidências de que fatores linguísticos como "formas de realização do pronome" e "concordância verbal" e fatores extralinguísticos como "escolaridade" podem ser altamente motivadores da realização do sujeito pleno. 
Em nosso trabalho, seguiremos basicamente os mesmos grupos de fatores testados pelas pesquisadoras, no entanto, enquanto elas se centraram em corpus de texto escrito, nosso corpus se constituirá de língua falada, podendo advir disso, quem sabe, alguma diferença estatística.

\section{METODOLOGIA}

\subsection{O locus da pesquisa}

A pesquisa foi empreendida na cidade de Florianópolis, mais precisamente em duas localidades da Ilha: Costa da Lagoa e Trindade. A primeira localidade é isolada, não urbana, alimenta costumes nativos, ilhéus, lusitano-açorianos. A segunda é um bairro universitário, localizado no miolo central da ilha, um bairro mais cosmopolita, e, talvez, portanto, mais suscetível a inovações linguísticas.

\subsection{Amostra}

Os dados que alimentam a nossa pesquisa foram extraídos de entrevistas sociolinguísticas realizadas por alunos da disciplina de Sociolinguística e Dialetologia ministrada no Programa de Pós-Graduação em Linguística da UFSC, no primeiro semestre de 2012. Optamos por extrair os dados das entrevistas a partir do vigésimo minuto de gravação, momento em que o falante demonstra estar mais envolvido com a sua narrativa, pois é nesses momentos de maior envolvimento que, segundo Labov, haveria um menor grau de atenção conferido à fala, vindo à tona, desse modo, o vernáculo do falante em toda a sua plenitude.

Foram analisadas as entrevistas de oito informantes, levando-se em

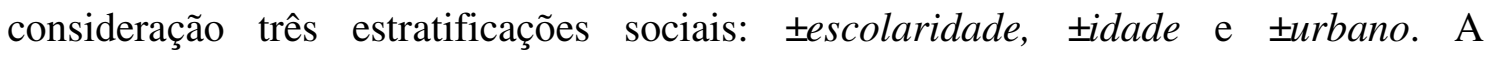
estratificação \pm escolaridade agrupa quatro falantes com Ensino Superior completo (+escolaridade) e quatro falantes com, no máximo, Ensino Médio completo (escolaridade). A estratificação tidade agrupa quatro informantes com idade acima de quarenta e seis anos (+idade) e quatro informantes com idade abaixo de 30 anos (idade). Por fim, a estratificação \pm urbano agrupa quatro informantes da Costa da Lagoa (-urbano) e quatro informantes da Trindade (+urbano). O Quadro 1, a seguir, distribui os oito informantes de acordo com as estratificações levadas em consideração:

\begin{tabular}{|c|c|c|c|}
\hline & Escolaridade & Idade & Urbano \\
\hline Informante 1 & + & + & + \\
\hline Informante 2 & - & - & + \\
\hline Informante 3 & - & + & + \\
\hline Informante 4 & + & - & + \\
\hline Informante 5 & - & + & - \\
\hline Informante 6 & + & + & - \\
\hline Informante 7 & + & - & - \\
\hline Informante 8 & - & - & - \\
\hline
\end{tabular}

Quadro 1 - Ficha catalográfica dos informantes 


\subsection{Envelope de variação}

Para esta pesquisa, nos valemos de sentenças declarativas com sujeitos pronominais anafóricos ou dêiticos preenchidos e nulos, sendo eliminados da análise sujeitos pronominais indeterminados. A partir das entrevistas, os dados foram transcritos e submetidos à descrição e análise, segundo as variáveis elencadas a seguir.

\subsubsection{Variável dependente}

A variável dependente aqui investigada é o preenchimento ou não do sujeito pronominal, ocorrido em sentenças declarativas da amostra utilizada. Duas variantes, portanto, constituem essa variável linguística: pronome preenchido e pronome nulo, como nos ilustram os dados abaixo extraídos das entrevistas:

(5) E aí, a gente não saía muito. (informante 1)

(6) Øgosta. Ø recebe bem. (informante 8)

\subsubsection{Variáveis independentes}

Lidaremos, em nossa pesquisa, com variáveis independentes de cunho linguístico e extralinguístico, a fim de examinarmos o grau de restrição que elas lançam sobre a emergência do preenchimento ou não do sujeito pronominal. Convém salientar que a nossa pesquisa tem um caráter preliminar e os dados serão calculados sem o uso de um pacote estatístico, impossibilitando-nos, desse modo, neste primeiro momento, de apontarmos com segurança e precisão matemática quais os fatores mais relevantes estatisticamente, bem como estabelecer um cruzamento entre as variáveis e apontar o peso relativo destas.

\subsubsection{Variáveis Linguísticas}

\section{Variável 'forma de realização do pronome'}

$\mathrm{Na}$ composição deste grupo de fatores, entram em cena os pronomes pessoais $e u$, tu, você/vocês, elelela, nós, a gente e eles/elas, ocupando a posição de sujeito da sentença, nulos e preenchidos. Abaixo, trazemos alguns dados que ilustram algumas dessas formas de realização:

(7) Ø tenho bastante amigos. (informante 8)

(8) Se tu for naquela praça dos bombeiros lá [...]. (informante 1)

(9) É a primeira pessoa que você entrevista? (informante 7)

(10) Ela é um córrego que vem do morro. (informante 2)

(11) Nós vínhamos descendo o morro e de repente [...]. (informante 4)

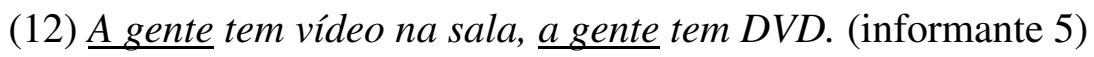


Ancorados nos trabalhos de Duarte (1993, 1995) e Nunes de Souza et al. (2010), a nossa expectativa é de que os pronomes que realizam concordância verbal canônica de terceira pessoa ('você'/'vocês', 'ele(a)/'eles(as)' e 'a gente') conduzam a uma maior tendência ao preenchimento do sujeito, uma vez que o núcleo Agr dessa desinência verbal não possui informação suficiente para identificar o referente discursivo inequivocamente, ou seja, é necessário o preenchimento do sujeito para se evitar ambiguidade.

Sobre os pronomes 'eu', 'nós' e 'tu', nossa expectativa é de que eles apresentem um hiato menor entre as taxas de preenchimento e não preenchimento, tendo em vista que concordam canonicamente com a $1^{\mathrm{a}}$ pessoa do singular, a $1^{\mathrm{a}}$ pessoa do plural e a $2^{\mathrm{a}}$ pessoa do singular, respectivamente, sendo essas desinências verbais não-ambíguas.

Ainda sobre o pronome 'tu', espera-se que ele, quando preenchido, não apresente concordância verbal canônica, pois, levando-se em consideração as investigações de Duarte (1993) e Figueiredo Silva (1996) sobre as mudanças nos paradigmas pronominal e flexional do $\mathrm{PB}$, acreditamos que o preenchimento da forma 'tu' é necessário em contrapartida ao progressivo desaparecimento da desinência verbal de $2^{\text {a }}$ pessoa do singular. As pesquisas sobre o paradigma pronominal vêm mostrando que o quadro de pronomes sujeitos dessa língua está em fase de mudança, encaminhando-se para uma configuração em que há somente distinção entre a $1^{\mathrm{a}}$ e a $3^{\mathrm{a}}$ pessoas, quanto à concordância verbal. Os resultados nos mostram que os dialetos de Florianópolis ainda conservam a desinência canônica de $2^{\mathrm{a}}$ pessoa do singular, no entanto, faz-se necessário averiguar quão recorrentes ainda são os usos dessa desinência.

\section{Variável 'concordância verbal'}

Para a composição desse grupo de fatores, apanhamos dados que apresentem concordância canônica e concordância não canônica. Ilustramos abaixo com dados extraídos das entrevistas:

(13) [...] mas tu não vais passar fome. (informante 7)

(14) [...] que sabem se tú tá fazendo o que tu precisa [...] (informante 6)

Esperamos, imbuídos dos pressupostos de Duarte $(1993,1995)$ e Tarallo (1992) e dos resultados obtidos por Nunes de Souza et al. (2010) para esse grupo de fatores, encontrar uma maior propagação do preenchimento do sujeito em contextos em que há menos concordância canônica e uma menor ocorrência de uso do sujeito preenchido em ambientes de concordância não canônica.

\subsubsection{Variáveis extralinguísticas}

\section{Variável 'localidade'}

Nessa variável, analisamos o grupo de fatores diatopia, buscando perceber se o eixo (+ urbano) ou (- urbano) afeta o padrão de uso do preenchimento do sujeito. Partindo do pressuposto de que a comunidade isolada da Costa da Lagoa apresenta um 
padrão linguístico mais conservador, mais próximo dos ancestrais lusitano-açorianos que colonizaram a Ilha de Santa Catarina, a nossa expectativa é de que os falantes nativos da Costa usem menos sujeito preenchido e de que os falantes do bairro Trindade façam mais uso do sujeito pronominal preenchido.

\section{Variável 'escolaridade'}

Compõe este grupo os fatores (+ escolarizado) e (- escolarizado). O primeiro inclui os falantes que concluíram ensino superior e o segundo grupo inclui falantes que fizeram apenas o ensino fundamental ou médio. Perseguindo a intuição de Nunes de Souza et al. (2010) quanto a esta variável, esperamos que os falantes mais letrados usem menos sujeito pronominal preenchido, seguindo, dessa forma, a manutenção do normativista princípio do "evite pronome" tal como batizado por Duarte (1993) em sua tese pioneira.

\section{A variável 'idade'}

Na composição desse grupo de fatores, dois fatores serão mobilizados:

(i) + jovens (menos de 30 anos)

(ii) - jovens (falantes de 45 anos em diante)

Sendo que o padrão mais antigo do PB era um maior uso de sujeitos nulos, esperamos que os falantes mais velhos se aproximem desse padrão mais conservador e que os falantes mais jovens mostrem uma gama maior de sujeitos preenchidos, o que nos indiciaria um caso de mudança em tempo aparente, nos termos labovianos.

\section{DESCRIÇÃO E ANÁLISE DOS RESULTADOS}

Antes de passarmos a analisar e discutir os dados, convém salientar que trabalharemos apenas com valores totais e percentuais, ou seja, os dados ainda não foram submetidos à análise mais precisa de um programa estatístico. Abaixo, visualizamos graficamente os percentuais de sujeito preenchido e sujeito nulo. Foram obtidos 893 dados distribuídos da seguinte forma: 
Gráfico 1 - Total de preenchimento do sujeito pronominal versus total de sujeito pronominal nulo

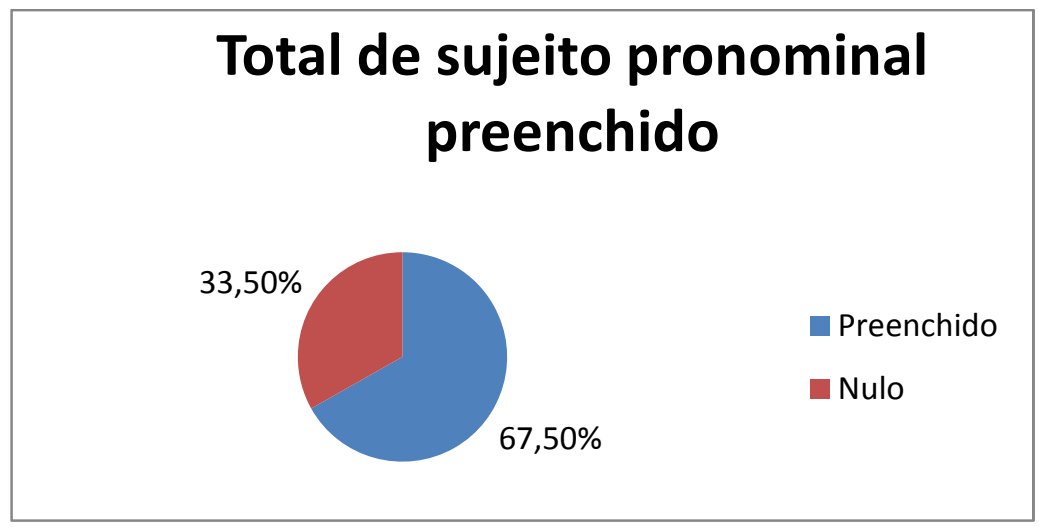

Os resultados evidenciam alta execução de preenchimento do sujeito pronominal na fala dos florianopolitanos inseridos na nossa amostra: 67,50\%, número que equivale a 603 dados da amostra. Esses índices se afinam, dessa forma, com os resultados obtidos por Nunes de Souza et al. (2010) em redações de alunos em escolas de Florianópolis. Mesmo em contexto mais formal, de texto escrito, as autoras, como vimos, obtiveram em sua análise $63 \%$ de preenchimento do sujeito pronominal, um índice muito próximo dos resultados que aqui auferimos.

Essa amplitude maciça de preenchimento do sujeito pronominal é compatível com o referencial teórico exposto neste artigo e as indicações dos estudos já realizados no PB sobre esse tema. Embora lidemos com uma amostra limitada, o que sempre nos estimula a evitarmos generalizações mais radicais e relativizarmos mais as nossas afirmações, vemos nesses resultados quantitativos uma evidência empírica satisfatória que confirma os resultados sobre os quais há um certo consenso entre diversos sociolinguistas que têm pesquisado esse assunto, consenso este pautado pela convicção de que o português brasileiro está saindo de um estágio de língua pro-drop para língua não pro-drop.

Esse comportamento linguístico na comunidade de fala florianopolitana se coaduna, portanto, com um padrão sintático que, aparentemente, se difunde pelo território brasileiro, sendo importante compará-lo, em discussões futuras, com outras pesquisas realizadas nas demais regiões do país.

\subsection{As variáveis linguísticas}

\section{Forma de realização do pronome}

Seguem os resultados para essa variável, de acordo com a Tabela 1: 
Tabela 1 - Preenchimento do sujeito pronominal, segundo a variável 'forma de realização do pronome'.

\begin{tabular}{c|cc}
\hline Forma de realização & Apl/Total & \% \\
\hline $\mathrm{Eu}$ & $248 / 388$ & 63,91 \\
\hline $\mathrm{Tu}$ & $24 / 33$ & 72,72 \\
\hline Você/Vocês & $10 / 13$ & 76,92 \\
\hline Ele(a)/Eles(as) & $153 / 223$ & 68,60 \\
\hline Nós & $24 / 57$ & 42,10 \\
\hline A gente & $144 / 148$ & 97,29 \\
\hline Total & $\mathbf{6 0 3 / 8 9 3}$ & $\mathbf{6 7 , 5 2}$ \\
\hline
\end{tabular}

Os resultados da Tabela 1 seguem a mesma direção do que se vê em Nunes de Souza et al. (2010), apontando para um maior preenchimento do sujeito pronominal das formas que fazem concordância canônica em $3^{\text {a }}$ pessoa (você/vocês, a gente, ele(a)/eles(as)). As autoras já fazem menção ao fato de que o maior preenchimento dessas formas se deve, provavelmente, à necessidade de retenção do pronome para se evitar ambiguidade, visto que não é possível recuperar o referente por meio da carga informacional do núcleo Agr, em razão da ausência da desinência de número.

Os pronomes 'eu' e 'nós' apresentaram menores taxas de preenchimento, justamente por apresentarem concordância canônica com a desinência verbal de $1^{\mathrm{a}}$ pessoa, uma desinência não-ambígua, que recupera o referente discursivo inequivocamente.

Um fato inesperado foi o de que o pronome 'tu' também se mostrou bastante preenchido $(72,72 \%)$. Poderia se esperar para esse pronome uma taxa de preenchimento similar ao das formas 'eu' e 'nós', visto que, em hipótese, o português falado nas comunidades pesquisadas em Florianópolis ainda conserva a desinência canônica de $2^{\text {a }}$ pessoa do singular (desinência não ambígua), com a qual a forma 'tu' pode concordar. $\mathrm{O}$ alto índice de preenchimento do pronome 'tu' pode ser melhor explicado se cruzado com suas taxas de concordância verbal, procedimento que tomaremos a seguir.

\section{Concordância verbal}

As taxas de preenchimento do sujeito pronominal de acordo com o fator concordância verbal foram listadas na Tabela 2, a seguir:

Tabela 2 - Preenchimento do sujeito pronominal, segundo a variável 'concordância verbal'.

\begin{tabular}{c|cc}
\hline Concordância verbal & Apl/Total & \% \\
\hline Concorda & $575 / 859$ & 66,90 \\
\hline Não concorda & $28 / 34$ & 82,35 \\
\hline Total & $\mathbf{6 0 3 / 8 9 3}$ & $\mathbf{6 7 , 5 2}$ \\
\hline
\end{tabular}

Os dados da Tabela 2 atestam a nossa hipótese anterior, formulada a partir dos pressupostos de Duarte (1993, 1995) e Tarallo (1992) e dos resultados obtidos por Nunes de Souza et al. (2010). O fator 'não concordância' apresentou uma taxa maior de preenchimento do sujeito pronominal $(82,35 \%)$ do que a taxa em contextos de concordância canônica $(66,90 \%)$. Essa constatação fortalece a tese de que é o nódulo Agr que rege a posição de sujeito nas línguas marcadas com parâmetro pro-drop positivo. Como Agr, em contextos de não concordância canônica, não tem informações

Work. Pap. Linguíst., 15(2): 86-102, Florianópolis, ago/dez, 2014 
suficientes para identificar inequivocamente o referente discursivo, faz-se necessário o preenchimento do sujeito pronominal para se evitar ambiguidade.

\section{Forma de realização do pronome $X$ concordância verbal}

Tabela 3 - Preenchimento do sujeito pronominal de acordo com o cruzamento entre 'forma de realização do pronome' $X$ 'concordância verbal'

\begin{tabular}{c|cc|cc}
\hline Forma de realização & Apl/Total & \% & Concorda & \% \\
\hline $\mathrm{Eu}$ & $248 / 388$ & 63,91 & $247 / 248$ & 99,60 \\
\hline $\mathrm{Tu}$ & $24 / 33$ & 72,72 & $3 / 24$ & 12,50 \\
\hline Você/Vocês & $10 / 13$ & 76,92 & $10 / 10$ & 100 \\
\hline Ele(a)/Eles(as) & $153 / 223$ & 68,60 & $148 / 153$ & 96,73 \\
\hline Nós & $24 / 57$ & 42,10 & $23 / 24$ & 95,80 \\
\hline A gente & $144 / 148$ & 97,29 & $144 / 144$ & 100 \\
\hline Total & $\mathbf{6 0 3 / 8 9 3}$ & $\mathbf{6 7 , 5 2}$ & $\mathbf{5 7 5 / 6 0 3}$ & $\mathbf{9 5 , 3 5}$ \\
\hline
\end{tabular}

Como podemos notar na Tabela 3, todas as formas pronominais apresentaram altas taxas de concordância quando preenchidas (taxas quase categóricas - acima de $95 \%$ ), exceto a forma 'tu' (apenas $12,50 \%$ de concordância). Essa constatação vai ao encontro da nossa hipótese inicial de que o 'tu', quando preenchido, apresentaria maiores índices de não-concordância, pois, aparentemente, o sistema pronominal do PB caminha para uma configuração em que há apenas distinção de concordância verbal na $1^{\mathrm{a}}$ e na $3^{\mathrm{a}}$ pessoa $^{8}$.

As formas 'eu' e 'nós' apresentaram concordância com a $1^{\mathrm{a}}$ pessoa verbal, enquanto as demais formas, incluindo o maior número de ocorrências do 'tu' (87,50\%), apresentaram concordância com a $3^{\mathrm{a}}$ pessoa. A concordância com a $2^{\mathrm{a}}$ pessoa se deu nas ocorrências de pro na $2^{\mathrm{a}}$ pessoa do singular e um minoritário caso de uso do 'tu' $(12,50 \%)$.

\subsection{As variáveis extralinguísticas}

\section{Escolaridade}

Os resultados para essa variável se encontram na Tabela 4, a seguir:

Tabela 4 - Efeito do grupo de fatores 'escolaridade' sobre a variável 'preenchimento do sujeito pronominal'

\begin{tabular}{l|l|l}
\hline Fator Escolaridade & Apl/Total & \% \\
\hline Mais escolarizado & $372 / 482$ & $77,17 \%$ \\
\hline Menos escolarizado & $231 / 411$ & $56,20 \%$ \\
\hline
\end{tabular}

Um dos grupos de fatores externos controlados neste artigo é 'escolaridade'. Partimos do pressuposto de que falantes mais escolarizados tenderiam a seguir o princípio "evite pronome". Dessa forma, falantes mais escolarizados usariam menos sujeito pronominal preenchido, tendência essa confirmada por Nunes de Souza et al.

\footnotetext{
${ }^{8}$ Essa hipótese ainda não pode ser tomada como forte, pois as ocorrências do pronome 'tu' na amostra investigada foram poucas em relação ao total de dados (24/893 ocorrências - 2,69\% do total).
}

Work. Pap. Linguíst., 15(2): 86-102, Florianópolis, ago/dez, 2014 
(2010), em cuja pesquisa o índice de sujeito pronominal preenchido foi despencando à medida que a escolaridade dos alunos avançava: de um peso relativo de 0,60 na quinta série para um peso relativo de 0,45 na oitava série. Os nossos resultados, contudo, seguem uma direção contrária, e nessa direção os dados dos falantes de maior escolaridade revelam um maior uso de preenchimento do sujeito pronominal: $77,17 \%$. Já no grupo menos escolarizado, a preferência pela forma preenchida de sujeito pronominal se mantém, porém com um índice menor: 56,20\%.

Como explicar tal diferença em relação aos resultados obtidos pelas pesquisadoras da UFSC? Aqui acreditamos que seria conveniente uma análise multivariada, cruzando o grupo de fatores escolaridade com o grupo de fatores 'forma de realização do sujeito pronominal', a fim de eliminar um provável enviesamento. Podemos argumentar também que, enquanto as autoras lidaram com texto escrito, um contexto de maior monitoramento e atenção conferidos à fala, os sujeitos de forma mais consciente evitaram repetir pronomes sujeito. Como estamos lidando com dados de língua oral, podemos perceber que, mesmo falantes mais escolarizados, nesse ambiente de oralidade, já se encontram menos sensíveis a esse princípio normativo do 'evite pronome', o que nos sinaliza a sugerir um avanço sem estigma social desse valor paramétrico - pro-drop no português brasileiro.

\section{Idade}

O grupo de fatores 'idade', segundo Labov (1972), pode revelar mudança observada na comparação entre diferentes faixas etárias. Muito mais do que uma categoria biológica, o fator idade, por metonímia, assume-se como estandarte dessas distintas configurações linguístico-sociais que gerações distintas podem revelar. Por isso, consideramos um fator social importante e altamente significativo para percebermos um avanço ou retração de determinado processo de mudança linguística. Não à toa, Labov (1972) considera possível afirmarmos que diferenças de padrão de uso em gerações distintas captadas pelo método sociolinguístico nos permitem vislumbrar um exemplo de mudança em tempo aparente.

Nossa expectativa, a priori, era de que os informantes do grupo (+ idade), em nosso corpus, fossem optar por uma quantidade maior de sujeitos pronominais nulos, adequando-se, dessa forma, a um sistema gramatical mais conservador, o sistema paramétrico + pro-drop. Entretanto, tal expectativa não se concretizou, pois esse grupo de informantes apresentou uma tendência de preenchimento do sujeito pronominal bastante equilibrada com a tendência dos informantes do grupo (-idade): a tendência de que falantes mais velhos $(70,37 \%)$ e falantes mais jovens $(64,84 \%)$ compartilham da mesma predileção pelo sujeito pronominal preenchido, como revelados na tabela a seguir:

Tabela 5 - Efeito do grupo de fatores 'idade' sobre a variável 'preenchimento do sujeito pronominal'.

\begin{tabular}{l|l|l}
\hline Fator Idade & Apl/Total & \% \\
\hline Até 30 anos & $299 / 461$ & $64,84 \%$ \\
\hline Mais de 45 anos & $304 / 432$ & $70,37 \%$ \\
\hline
\end{tabular}

Tal índice nos faz sugerir uma noção bastante cara à teoria sociolinguística: se falantes mais velhos, de gerações mais antigas, já mostram um comportamento linguístico tido como mais inovador no sistema da língua, torna-se viável pensar em um avanço mais rápido na curva do processo de mudança, o que nos faz sugerir também

Work. Pap. Linguíst., 15(2): 86-102, Florianópolis, ago/dez, 2014 
que esse processo de mudança já começara em geração ainda mais remota, não captada pelo nosso universo de entrevistados investigados neste trabalho. O que aqui estamos afirmando vai ao encontro de que Duarte (1993) já havia apresentado em sua tese.

$\mathrm{O}$ fato é que os resultados obtidos em nossa pesquisa nos municiam a sugerir que o preenchimento do sujeito pronominal avança imune ao grupo de fatores escolarização, pelo menos na oralidade, e também avança sem ser afetado pelo grupo de fatores idade. Dessa forma, podemos sugerir que estamos diante de um processo que não carregaria significação social pejorativa, ao mesmo tempo em que seria compartilhado por gerações mais novas e mais velhas, tornando-se assim um fenômeno com forte tendência a consolidar-se de vez no sistema gramatical do português brasileiro. Porém, afirmar isso com segurança demandaria uma quantidade maior de pesquisas. Por ora, tudo é sugestão tímida, advinda de um universo limitado de dados.

\section{Localidade}

Quando estamos diante de duas localidades tão distintas como Trindade e Costa da Lagoa, há de se esperar que pudéssemos encontrar tendências distintas de uso entre padrões inovadores e padrões mais conservadores. Para informações mais detalhadas sobre a configuração histórico-demográfica-espacial da Costa da Lagoa sugerimos a leitura da dissertação de Gimeno (1992) "O destino viaja de barco: um estudo histórico, político e social da Costa da Lagoa e seu processo de modernização" bem como uma leitura da tese de Souza (2001) "Estudo demográfico, antropológico e genético das populações da Costa da Lagoa e de São João do Rio Vermelho".

Em relação à variável linguística em estudo, os falantes da Costa da Lagoa mostram uma tímida predileção pelo padrão sintático mais conservador, em torno de $63 \%$, como revelam os resultados da Tabela 6 , a seguir:

Tabela 6 - Efeito do grupo de fatores 'localidade' sobre a variável 'preenchimento do sujeito pronominal'

\begin{tabular}{l|l|l}
\hline Fator localidade & Apl/Total & $\%$ \\
\hline Costa da Lagoa & $308 / 484$ & $63 \%$ \\
\hline Trindade & $295 / 409$ & $72 \%$ \\
\hline
\end{tabular}

Por sua vez, os falantes do bairro Trindade mostraram um resultado maior do padrão sintático inovador (72\%). Essa diferença já norteava a nossa hipótese a princípio, considerando o padrão de vida mais conservador e pacato da comunidade da Costa da Lagoa. Contudo, esperávamos uma diferença de padrão de uso mais larga entre as duas comunidades, algo que não ocorreu em nossos resultados. Um cruzamento dessa variável com outro grupo de fatores poderia resolver um eventual enviesamento de dados. De alguma forma, os índices obtidos no grupo de fatores 'localidade' não deixam de revelar também o avanço notório do padrão sintático de preenchimento do sujeito pronominal, padrão este sobre o qual os fatores sociais parecem não se constituir como contexto de retenção à forma inovadora. 


\section{CONSIDERAÇÕES FINAIS}

Neste artigo, perseguimos uma descrição sobre a realização do sujeito pronominal (pleno ou nulo) no português brasileiro através de dados obtidos de falantes de duas comunidades da cidade de Florianópolis: Trindade e Costa da Lagoa. Ao final deste texto, podemos concluir que o padrão sintático inovador avança cada vez mais para uma consolidação em seu estágio de parâmetro pro-drop negativo. Averiguamos também que esse processo passa ao largo de fatores sociais, o que permite que essa transição entre dois estágios ocorra de forma mais célere, sem pontos de retração na escala social. Auferimos também o quanto restrições internas ainda atuam fortemente sobre esse fenômeno variável, como, por exemplo, o papel inibidor do componente AGR sobre o preenchimento do sujeito pronominal.

Acreditamos, dessa forma, ter contribuído com a compreensão desse fenômeno variável e esperamos que comparações com outros estudos sobre esse tema sejam feitas na tentativa de rastrear com mais apuro certas especificidades dessa disputa envolvendo os dois padrões sintáticos aqui estudados.

\section{REFERÊNCIAS}

CHOMSKY, N. Lectures on government and binding. Dordrecht: Foris, 1981.

DUARTE, M.E.L. Do pronome nulo ao pronome pleno: a trajetória do sujeito no Português do Brasil. In: I. Roberts, M. A. Kato. (orgs.) Português Brasileiro - uma viagem diacrônica. Campinas: Editora da Unicamp, 1993.

A perda do princípio ''Evite Pronome"' no Português Brasileiro. Tese (Doutorado). Campinas: UNICAMP,1995.

FIGUEIREDO SILVA, M. C. A posição sujeito no português brasileiro: frases finitas e infinitivas. Campinas, São Paulo: Editora da UNICAMP, 1996.

GIMENO, S. I. D.. O destino viaja de barco: um estudo histórico, político e social da Costa da Lagoa e de seu processo de modernização. Dissertação (Mestrado): Universidade Federal de Santa Catarina, 1992.

LABOV, W. Sociolinguistic Patterns. Philadelphia: University of Pensylvania Press, 1972.

MODESTO, M. Sujeitos nulos em línguas de tópico discursivo proeminente. Revista ABRALIN, vol. III, $\mathrm{n}^{\circ}$ III, p. 119-145, 2004.

NUNES DE SOUZA et al. O preenchimento do sujeito pronominal em textos escritos de alunos adolescentes de Florianópolis. In: Work. Pap. Linguist., p. 94-107. Florianópolis: 2010.

SOUZA, I. R. de. Estudo demográfico, antropológico e genético das populações da Costa da Lagoa e de São João do Rio Vermelho, na Ilha de Santa Catarina. Tese (Doutorado). Curitiba: Universidade Federal do Paraná, 2001.

TARALLO, F; KATO. Harmonia Trans-sistêmica: variação intra e inter-linguística. In: Revista Diadorim. Rio de Janeiro: Ed. UFRJ, 2011, $2^{\text {a }}$ Ed, p. 13-43. 
TARALLO, F. Diagnosticando uma gramática brasileira: o português d'aquém e d'além-mar ao final do século XIX. In: In: I. Roberts, M. A. Kato. (orgs.) Português Brasileiro - uma viagem diacrônica. Campinas: Editora da Unicamp, 1992.

WEINREICH, U; LABOV, W; HERZOG, M. Empirical foundations for a theory of language change. In: LEHMAN, MALKIEL. (Ed) Directions for historical linguistics. Austin, University of Texas Press, 1968.

Data de submissão: 14/06/2013

Data de aceite: 16/10/2013 